\title{
Corpo privado da liberdade e o esporte: perspectivas educacionais
}

\author{
Bodies deprived of freedom and sport:
}

educational perspectives

Cuerpo privado de libertad y deporte:

perspectivas educativas

LAUDETH ALVES DOS REIS (D)

WAGNER WEY MOREIRA (iDb

\section{Resumo}

Esse artigo objetiva analisar como os integrantes de uma instituição socioeducativa de internação compreendem o corpo e as possibilidades educativas da prática esportiva, nesse universo de controle corporal. Trata-se de uma pesquisa qualitativa, com enfoque fenomenológico do tipo descritivo. A investigação teve como cenário um centro socioeducativo em regime de privação de liberdade situado em cidade localizada no Triângulo Mineiro, MG, Brasil. A coleta dos dados foi realizada por meio de entrevista estruturada. Evidenciou, a partir dos dados, maior incidência na concepção de corpo dos adolescentes a visão dicotômica do corpo, já os agentes socioeducativos o conceberam como objeto manipulável. Em relação ao potencial educativo do esporte, os adolescentes apontaram como papel fundamental a formação humana e cidadã e

\footnotetext{
a Núcleo de Estudos e Pesquisas em Corporeidade e Pedagogia do Movimento (NUCORPO), Universidade Federal do Triângulo Mineiro (UFTM), Uberaba, Minas Gerais, Brasil. Mestre em Educação, e-mail: laudeth.alves@outlook.com

${ }^{\text {b }}$ Núcleo de Estudos e Pesquisas em Corporeidade e Pedagogia do Movimento (NUCORPO), Universidade Federal do Triângulo Mineiro (UFTM), Uberaba, Minas Gerais, Brasil. Doutor em Educação, e-mail: weymoreira@uol.com.br
} 
os agentes socioeducativos, ratificaram o poder disciplinar do corpo. Conclui-se que os discursos dos adolescentes e dos agentes socioeducativos partem para caminhos, ora divergentes, ora convergentes, sendo indispensáveis mais estudos, pesquisas e reflexões sobre o corpo e o esporte nestas instituições privativas de liberdade.

Palavras-chave: Corpo. Privação de liberdade. Adolescente. Esporte.

\begin{abstract}
This study aimed to analyze how members of a juvenile socio-educational center understand the body and the educational possibilities of sports practice in such a universe of body control. It deals with qualitative research of the phenomenological approach and of the descriptive type. The research took place in a socio-educational juvenile center working in the regime of freedom deprivation and located in a city of the Triângulo Mineiro region, MG, Brazil. Data came from structured interviews. Results showed a higher incidence of a dichotomous vision of the body among the conceptions posed by the center members since its socio-educational agents conceived the body as a usable object. Regarding the educational potential of the sport, the center members pointed out the human and citizen training a fundamental result, while its socioeducational agents ratified the disciplinary power of the body. It is concluded that the discourses of adolescents and socio-educational agents are heading towards paths, sometimes divergent, sometimes convergent, being indispensable more studies, researches and reflections on the body and sport in these institutions deprived of freedom.
\end{abstract}

Keywords: Body. Freedom deprivation. Adolescents. Sport.

\title{
Resumen
}

Este artículo pretende analizar cómo los miembros de una institución socio-educativa de internamiento entienden el cuerpo y las posibilidades educativas de la práctica deportiva, en este universo de control corporal. Se trata de una investigación cualitativa con un enfoque fenomenológico de tipo descriptivo. La investigación tuvo como escenario un centro socio-educativo en régimen de privación de libertad situado en una ciudad ubicada en Triângulo Mineiro, MG, Brasil. Los datos se reunieron mediante entrevistas estructuradas. A partir de los datos, mostró una mayor incidencia en la concepción de los cuerpos de los adolescentes la visión dicotómica del cuerpo, ya que los agentes socio-educativos lo concibieron como un objeto manipulable. En relación con el potencial educativo del deporte, los adolescentes señalaron como un papel fundamental la formación humana y ciudadana y los agentes socioeducativos ratificaron el poder disciplinario del organismo. Se concluye que los discursos de los adolescentes y los agentes socioeducativos comienzan a recorrer caminos, a veces 
divergentes, a veces convergentes, siendo imprescindible más estudios, investigaciones y reflexiones sobre el cuerpo y el deporte en estas instituciones privadas de libertad.

Palabras clave: Cuerpo. Privación de la libertad. Adolescente. Deporte.

\section{Introdução}

Esse artigo é resultante de uma pesquisa desenvolvida em 2019 por dois professores, um deles docente do Programa de Mestrado e Doutorado em Educação da Universidade Federal do Triângulo Mineiro - UFTM, e o outro pedagogo de uma instituição socioeducativa. Ambos desenvolveram palestras e programas na referida Instituição tratando do tema esporte e a relação desse com o dia a dia dos internos.

As intervenções realizadas na instituição nos permitiram fazer os seguintes questionamentos: o que os adolescentes privados de liberdade e os agentes socioeducativos pensam sobre o corpo? A prática esportiva dentro da instituição socioeducativa é realmente uma possibilidade educativa e emancipatória?

Daí razão do presente artigo, o qual tem como objetivo analisar como os integrantes de uma instituição socioeducativa de internação compreendem o corpo e as possibilidades educativas da prática esportiva nesse universo de controle corporal.

Para tanto, estruturamos o presente trabalho em três momentos: no primeiro, refletiremos sobre o fenômeno corpo/corporeidade, em especial quando este ser corporal perde a possibilidade da liberdade; no segundo, caminhamos no sentido de identificar as possibilidades educativas do esporte, quando propõe a criação e a vivência de valores necessários para a vida comunitária; no terceiro, realizamos uma pesquisa de campo junto aos adolescentes privados de liberdade e aos agentes socioeducativos que trabalham na instituição, interpretando os dados coletados nas entrevistas e relacionando-os aos elementos teóricos apresentados.

Podemos justificar o trabalho enfatizando duas trilhas: a primeira, porque acreditamos nas possibilidades educacionais do conhecimento e a da prática do fenômeno esporte, considerando que este pode estabelecer a vivência de valores necessários para uma autonomia individual e coletiva como a corresponsabilidade na interação com os outros (colegas de time e adversários), o reconhecimento de 
atitudes éticas e estéticas, o exercitar a disciplina e as autodisciplinas, dentre outros; a segunda é permitir, via prática esportiva, a convivência prazerosa mesmo num ambiente pouco propício à manifestação desta.

\section{Corpo/corporeidade: valores educacionais para a liberdade}

Trazer apontamentos a respeito de um corpo privado de liberdade sob a égide da corporeidade, torna-se um grande desafio pelo fato da circunstância de cerceamento do direito de ir e vir, uma vez que estar em espaço fechado, sem dúvida, já é por si só, uma forma de punição.

A princípio, vale situar a condição do adolescente privado de liberdade que, por alguma circunstância, cometeu ato infracional. Como consequência, leva-o a internação como a última medida socioeducativa, considerada gravíssima e, segundo o Estatuto da Criança e do Adolescente ECA (BRASIL, 1990), medida essa que ele melhor poderá responder legalmente. Ainda que possua uma dimensão coercitiva, a medida é de cunho pedagógico, considerando o ato educativo como sua principal via de reinserção na sociedade. Possui durabilidade de até três anos, sendo reavaliada, no máximo a cada seis meses, mediante decisão do Juiz da Vara da Infância, fundamentada por equipe técnica multidisciplinar da instituição.

Durante a privação de liberdade há uma perda de autonomia do adolescente, pois precisa se adequar às regras da instituição, cujas ações são rigorosamente controladas e, consequentemente, diminui a capacidade de se movimentar que é própria do ser humano.

No processo de acautelamento, muitas são as formas de se autossuperar, sobretudo na condição de adaptação a esse meio considerando as restrições de suas ações. Aliás, há uma busca permanente de movimentos que são apre(e)ndidos diariamente e passam a ter sentido na vida. A esse respeito, Moreira e Simões (2011) e Assmann (2012, 1995), sinalizam uma corporeidade aprendente, uma vez que ninguém escapa ao ato educativo, um processo dinâmico e contínuo.

Para Moreira e Simões (2011), aprender demanda esforço, motivação e, mesmo no enfrentamento as dificuldades, existe prazer, pois há uma incorporação 
do aprendido, dotada de significados que tendem a se consolidar como novos conhecimentos.

Em seu discurso sobre o corpo, Le Breton (2012) não o considera com mero veículo da pessoa e sim, um universo que denota representações, sentidos e valores, pois é na relação com os outros e o mundo que se vai descobrindo e se constituindo como pessoa. Por isso, o autor aponta a compreensão da corporeidade como um fenômeno social e cultural que permite a pessoa descobrir-se nessa conexão, que vai sendo estabelecida rumo à construção de sua identidade.

No cumprimento da medida socioeducativa há uma demanda de procedimentos disciplinares, própria da condição legal de uma instituição de segurança pública a qual os adolescentes são submetidos a um conjunto de normas impostas, de acordo com o regimento institucional, como por exemplo: frequentar as atividades escolares; tomar medicação; cuidar da higiene pessoal, do alojamento e demais espaços de convivência e outros. Santin (2011) nos alerta, ao tratar da corporeidade disciplinada, que implica na compreensão do corpo o quanto este se sacrifica em detrimento de uma ordem social ou cultural, na condição de submissão e obediência às tarefas determinadas.

Esses corpos representam em si instrumentos a serviço da razão e, se considerados ignorantes e analfabetos, facilmente se reduzem à mera ferramenta nas mãos de esferas dominantes (ALTHUSSER, 2010)

Nesse estudo, sem a pretensão de apresentar soluções e sim, possibilidades para uma fecunda reflexão é que nos propusemos ao entendimento da concepção de corpo e suas possibilidades educativas via esporte, na perspectiva da corporeidade, privilegiando o sentido de existir e não o de reproduzir.

No esporte, se nossa visão é entender o ser que joga, não basta nos preocuparmos com as técnicas e os rendimentos, mas sim com o corpo que se movimenta na busca de ser mais, se autossuperando, condição vital do desenvolvimento humano.

Abordar o corpo e seus valores educativos para a liberdade é entendê-lo como vida que pulsa, pois segundo Moreira (2012, p. 135) falar em educação corporal é: “[...] falar de uma aprendizagem humana, é aprender de maneira humana (por isso existencial) a ser homem, a existir como ser humano. Falar de uma 
educação do corpo é explicitar a corporeidade". É reconhecer o ser humano como corporeidade, na sua totalidade como ser complexo e marcadamente cultural, saindo da visão dualista cartesiana, que o fragmentou e reduziu em corpo e mente.

A corporeidade permite aos seres humanos a compreensão de palavras que hoje pouco sentido têm na relação com a preocupação para o entendimento do humano: sentir, agir, pensar, ousar, sonhar, criar e transcender, dentre outras.

Dar sentido à corporeidade requer, em sua essência, superar a dualidade que tanto percorreu tangenciando uma ideia de corpo fragmentado. E se fizermos isto via propostas pedagógicas a serem aplicadas junto a adolescentes e adultos, propiciará o entendimento de uma educação com bases fenomenológicas, em que educar é colocar a relação educador-educando a serviço do conhecimento da cultura em sua história. "Educar-se é aprender a fazer a história, fazendo cultura" (REZENDE, 1990, p. 63).

Acreditamos na possibilidade de ações compreendidas a partir do sentido da corporeidade que permita uma reformulação de valores e atitudes, lembrando que toda ação humana é a priori corpórea e, portanto, passível de mudança, num processo contínuo de reaprender a ver o mundo na sua complexidade. Sobre isso, Nóbrega (2005, p. 68) ressalta que a aprendizagem trata de uma nova organização da corporeidade, pois "Quando aprende, quando encontra um sentido e uma significação para um acontecimento em sua existência, o ser humano passa a habitar o espaço e o tempo de uma forma diferente".

Sendo assim, a educação enquanto fenômeno humano reside na capacidade de aprender permanentemente, o que diferencia o homem dos animais, pois esses encontram-se presos aos limites de suas condições naturais, enquanto o primeiro na complexidade e amplitude de conhecimentos inerentes ao seu ser, consegue reconhecer, a partir de um determinado ponto, diferentes perspectivas (REZENDE, 1990; NÓBREGA, 2005). E são essas diferentes perspectivas que o adolescente infrator pode experimentar dentro do contexto a que pertence.

Está claro que mesmo o espaço socioeducativo sendo restritivo ao corpo, impedindo o direito de ir e vir, trata-se de um espaço propício à reinvenção das relações humanas, o que pressupõe a expressão da corporeidade, como presença viva e ativa de um ser existencial. Significa um desafio à imaginação e criatividade. 
Se, por um lado, identificamos uma instituição que controla, monitora e disciplina os adolescentes que ali se encontram, por outro, devemos lembrar que os mesmos estão numa fase da vida repleta de transformações e muitas incertezas, fato esse agravado pela diversidade sociocultural e socioeconômica a qual se inserem. $\mathrm{O}$ que demanda dos profissionais que ali atuam uma preocupação maior se pautados no cunho educativo.

Entendemos aqui uma corporeidade sensível e inteligível, liberta do que possa oferecer riscos a si próprio. Daí a importância de se ampliar o entendimento da corporeidade, superando o olhar racional e controlador, uma vez que a medida intrinsecamente se caracteriza como coercitiva e educativa (VOLPI, 2011), de maneira que o adolescente reconheça o erro e possa repará-lo, ressignificando seu projeto de vida.

Gonçalves (2012, p. 13), a esse respeito, aponta: “O corpo de cada indivíduo de um grupo cultural revela, assim, não somente sua singularidade pessoal, mas também tudo aquilo que caracteriza esse grupo como uma unidade".

Pensar o corpo numa instituição socioeducativa, enquanto território identitário que acarreta temporalidades, implica transcender sua compreensão numa visão reduzida à disciplina, controle e submissão, mas que as ações ali propostas possam promover a reflexão. Deve-se, pois, superar a instrumentalização e compreensão da corporeidade, como princípio epistemológico, capaz de dar novos significados à condição corporal restritiva do adolescente, avançando assim nas propostas socioeducativas.

Por isso é que calcados na perspectiva dos estudos da corporeidade, cujo entendimento requer mudança de valores, nos propusemos nesse artigo elucidar os valores educacionais para a liberdade, de modo que suscite nos adolescentes o sentido de um corpo que pensa, sente, age, se relaciona com outros corpos, sonha e busca concretizar projetos (presentes e futuros) individuais e coletivos, rumo a uma vivência concreta da cidadania, em meio a um ambiente estimulante. 


\section{Corpo aprisionado e esporte: possibilidades educativas para a liberdade?}

Aqui nos apropriamos da expressão corpo aprisionado (FOUCAULT, 2013; LE BRETON, 2012) para designar os adolescentes privados de liberdade dentro do contexto no qual se encontram, segundo a perspectiva de vivência do fenômeno corporeidade, a partir da complexidade de seu entendimento de corpo, bem como as possibilidades educativas que do esporte possam emergir.

Silva e Rubio (2008) sublinham o esporte como um meio de desenvolvimento das várias potencialidades humanas, capaz de suplantar a visão de aprendizado não como mera técnica e instrumento de atividade corporal, mas sim fator essencial de desenvolvimento integral do sujeito. E isso, independe da sua condição de privação de liberdade ou não, até porque o esporte se insere nos diferentes espaços culturais e sociais.

Esses mesmos autores (SILVA; RUBIO, 2008) e Domingos (2014) evidenciam o esporte como um instrumento importante no contexto socioeducativo, além de revelarem a carência de produção científica e metodologias próprias favoráveis a uma prática esportiva comprometida com a formação plena desses adolescentes.

O esporte historicamente demonstrou, e ainda demonstra, a força de buscar seu destino fugindo às possibilidades de ser uma pedagogia de amestrar corpos. Isto permite caminharmos no sentido da compreensão do que seja corporeidade, perspectivando a possibilidade do ser na busca de se conhecer, conhecer melhor os outros e o mundo comprometendo-se com uma vivência cidadã. De acordo com Gonçalves (2012, p. 176) "Conceber a corporeidade integrada na unidade do homem significa resgatar o sentido do sensível e do corpóreo na vida humana".

No ambiente socioeducativo, locus da pesquisa, o esporte representa uma atividade altamente prazerosa. A esse respeito, Moreira e Simões (2018, p. 166) salientam que:

O conhecimento e a prática do esporte nos permitem a vivência de emoções e sentimentos e o cultivo de sensações de entusiasmo e admiração, possibilitando 
novas formas de sentir a vida, com o corpo como um todo, e tornando-nos, assim, apaixonados de coração e alma. Essas características definem o ser humano e devem fazer parte do nosso projeto político como integrantes da humanidade.

Moreira e Simões (2018) ainda assim, enfatizam o esporte como próprio da formação humana e ratificam que não deve ser reduzido apenas às dimensões técnicas e de rendimento, mas também ao desenvolvimento da dimensão do fenômeno humano na busca da humanização.

Todo movimento é carregado de significados e é essa necessidade de mover que garante a vida e permite a expressão da corporeidade, independente da condição de liberdade ou acautelamento que se encontra o indivíduo. O que se evidencia neste estudo, a compreensão do corpo na prática esportiva sob a perspectiva dos atores envolvidos, principalmente quando esse — o esporte — se propõe valorizar as diferentes potencialidades dos adolescentes.

Assim, se essa prática for conduzida segundo os valores educacionais a que se propõe, pode se tornar um excelente mecanismo que permita aos adolescentes privados de liberdade, corpos considerados aprisionados, vivenciar a liberdade inerente ao esporte, mesmo porque de acordo com Gonçalves (2012), seu caráter lúdico proporciona prazer, uma característica própria do homem ao brincar.

Kunz $(2014,2012)$ se ocupou em analisar o esporte sob a perspectiva pedagógica, para um ensino crítico-emancipatório, discorrendo uma compreensão mais abrangente enquanto fenômeno sociocultural e histórico. Além disso, considera sua forte influência nos estilos e formas próprias de características que assume em diferentes contextos. Assim, entendemos que sua intencionalidade pedagógica não se restringe apenas em auxiliar tecnicamente o adolescente, mas que participe com autonomia e, acima de tudo, assuma uma reflexão crítica sobre todas as formas da prática esportiva.

Outro teórico a chamar a atenção para as possibilidades do esporte enquanto fenômeno emancipatório do ser humano é Bento (2004, p. 63) ao declarar que o esporte lida diretamente com a função de humanização. Tal é sua veemência neste sentido que afirma: "Talvez cheguemos assim a concluir que, sem desporto, o envolvimento cultural dos homens empobrece, torna-se descarnado e ressequido de emoções e paixões". 
O mesmo autor elenca, em discurso proferido por atletas, valores adquiridos na vivência esportiva e que influenciaram permanentemente suas vidas. Procurando sintetizar os relatos (BENTO, 2004, p. 79, 80) apontamos: adquirir comportamentos de harmonia necessários para o sucesso tanto da equipe quanto do dia a dia na vida; assumir o risco de tomar decisões, necessidade muito comum na prática esportiva e talvez, em muitos momentos da vida; cultivar a imaginação e a criatividade; desenvolver o hábito da resistência e da persistência; mobilizar forças e energias para se alcançar os objetivos traçados.

Cabe, portanto, oportunizar espaços de aprendizagens contextualizadas, propiciando a exploração dos seus potenciais corporais e relações interpessoais. Nista-Piccolo e Moreira (2012a, p. 32), apontam:

Ter direito de conhecer e praticar esportes significa apossar-se das técnicas para conquistar mais e caminhar na direção de se conhecer melhor, de conhecer os outros de maneira mais humana, e apreciar o mundo e as coisas num estilo de vida com qualidade.

A prática esportiva trata de um momento propício para que se possa vivenciar diferentes valores como: um exercício de respeito mútuo; a responsabilidade social e trabalho coletivo quando, por exemplo as diferenças são esquecidas e relevadas num momento de partida de futebol. Esse é um instante oportuno para se levar em conta as próprias potencialidades e limitações, além da diversidade dos modos de ser, pensar e agir.

Vemos que a prática do esporte demanda regras, disciplina e submissão, mas vale destacar que nem todos estão preparados para esse tipo de exigência. É nesse sentido que se faz necessário um olhar atento aos postulados de Foucault (2013) ao tratar dos corpos dóceis, cuja disciplina - sob uma ótica verticalizada - se encarrega de formar corpos submissos, regulando rigorosamente os gestos e os comportamentos. E isto o autor define como a formação de uma política de coerções que implicam no domínio dos corpos. No entanto, precisamos rever o esporte numa perspectiva transformadora, de modo que promova a humanização e a emancipação, em especial dos adolescentes, foco do presente estudo.

De acordo com as diretrizes pedagógicas do sistema socioeducativo (MINAS GERAIS, 2016), a disciplina é considerada um instrumento norteador do trabalho 
educativo destas instituições. O que significa pensá-la de forma diferente, não apenas como ato de controle, mas sim no prisma do entendimento de uma forma mais aberta às regras, bem como a compreensão da realidade que os cerca, propiciando o desenvolvimento de sua autonomia. E, encontramos no esporte, um vetor ao compromisso educacional, que possibilitará, desse modo, um ambiente propagador de cultura e conhecimento, capaz de promover mudanças de atitudes e aquisições de valores.

É importante destacar a compreensão dos profissionais que atuam no sistema socioeducativo a respeito do esporte, para que seja valorizada sua presença no âmbito institucional, pois pode ser um excelente mecanismo de ação na ressocialização dos adolescentes privados de liberdade, se analisada a sua função social, redimensionando os valores a ele atribuídos. Faz-se necessário entendê-lo como elemento possível e inevitável ao ato educativo.

Necessária também a tarefa de levar os adolescentes a esse conhecimento de esporte e a essa vivência da corporeidade. No tocante, Nista-Piccolo e Moreira (2012b, p. 74) salientam que:

[...] conhecendo e praticando esportes poderão reconhecer princípios éticos vivenciando as regras estabelecidas para melhor convivência entre eles, adquirindo hábitos saudáveis para toda a sua vida, e ainda desfrutar de valores educacionais, razão maior de nossa atuação profissional.

Para ilustrar o presente estudo, se realizou uma pesquisa de campo junto a adolescentes privados de liberdade e agentes socioeducativos, interpretando os dados coletados nas entrevistas e relacionando-os aos elementos teóricos apresentados.

\section{Metodologia da pesquisa de campo}

O aporte metodológico deste artigo é de pesquisa qualitativa, com um enfoque fenomenológico (GIORGI, 1978; MARTINS; BICUDO, 2005) do tipo descritivo (GIL, 2017), porque se preocupa em analisar e interpretar as vivências reveladas e expressas segundo os sujeitos envolvidos. 
Para a análise dos dados referentes aos discursos dos participantes da pesquisa, utilizou-se a Técnica de Elaboração e Análise de Unidades de Significado, elaborada por Moreira, Simões e Porto (2005).

A pesquisa foi realizada numa instituição socioeducativa em regime de privação de liberdade situado em cidade localizada no Triângulo Mineiro, Estado de Minas Gerais. Os sujeitos participantes do estudo foram 16 (dezesseis) adolescentes privados de liberdade que representam $73 \%$ da capacidade total de atendimento e 10 (dez) agentes socioeducativos, contemplados em dois turnos diurnos, representando $46 \%$.

O grupo de adolescentes privados de liberdade têm entre 15 e 19 anos, todos do sexo masculino e os agentes socioeducativos, entre 25 e 49 anos, sendo 04 (quatro) do sexo feminino e 06 (seis) do sexo masculino.

Para o instrumento de coleta de dados utilizou-se uma entrevista estruturada (MACEDO, 2010) a partir das seguintes questões geradoras, sendo duas direcionadas aos adolescentes: "O que é corpo pra você?" e "A prática esportiva educa? Como?" e, outras duas, aos agentes socioeducativos: “O que é o corpo adolescente em privação de liberdade?” e "A prática esportiva educa? Como?”.

Para a realização dessa etapa, partimos para um contato prévio com a direção da instituição salientando os objetivos da pesquisa, formalizando o convite e esclarecendo sobre o Termo de Consentimento Livre e Esclarecido (TCLE), para então realizar o contato e trâmites legais com os possíveis sujeitos da pesquisa. A entrevista foi realizada na sala da Pedagogia da instituição, sendo o atendimento de forma individualizada para não haver interferências de outros sujeitos.

No âmbito da análise dos discursos dos participantes utilizamos a Técnica de Elaboração e Análise de Unidades de Significado (MOREIRA; SIMÕES; PORTO, 2005) que constitui três momentos: o relato ingênuo; a identificação de atitudes e a interpretação das informações sob a forma de discursos escritos, indicadores significativos revelados nas falas dos sujeitos, buscando identificar, sem o intuito de generalização, convergências e as divergências presentes em suas respostas.

Para a identificação das falas dos sujeitos, optamos por numerar da seguinte forma: para os adolescentes utilizamos SAD 1, SAD 2, SAD 3... e para os agentes socioeducativos SASE 1, SASE 2, SASE 3... 
Destacamos, ainda, que a pesquisa foi autorizada pelo Comitê de Ética em Pesquisa (CEP) da UFTM, sob o parecer CEP: No 1.343.986.

\section{Resultados e discussão}

Atendendo aos pressupostos da análise de dados escolhida, apresentamos as Unidades de Significado (US) (MOREIRA; SIMÕES; PORTO, 2005) de cada pergunta, de forma minuciosa e a sistematização das respostas dos sujeitos, demonstradas em forma de tabelas, revelando assim os fenômenos analisados. Para tanto, elencamos algumas informações mais relevantes, em nossa interpretação, para o entendimento dos fenômenos corpo e esporte nas palavras dos sujeitos da pesquisa, mantendo sua linguagem, na íntegra.

Quando os adolescentes foram indagados sobre "o que é corpo pra você" as respostas nos possibilitaram inferir 05 (cinco) Unidades de Significado (US) como demonstra a Tabela 1:

Tabela 1 - Unidades de significado da pergunta geradora aos adolescentes "O que é corpo pra você?"

$\begin{array}{llllllllllllllllll}\text { SUJEITOS } & 1 & 2 & 3 & 4 & 5 & 6 & 7 & 8 & 9 & 10 & 11 & 12 & 13 & 14 & 15 & 16 & \mathrm{~T}\end{array}$

UNIDADES DE

SIGNIFICADO

\begin{tabular}{l|l|l|l|l|l|l|l|l|l|l|l|l|l|l|l|l|l|}
\hline $\begin{array}{l}\text { 1. Conjunto de órgãos } \\
\text { e peças conexos, } \\
\text { como uma máquina }\end{array}$ & & $\mathrm{x}$ & $\mathrm{x}$ & & $\mathrm{x}$ & & & & $\mathrm{x}$ & $\mathrm{x}$ & & & & $\mathrm{x}$ & $\mathrm{x}$ & $\mathrm{x}$ & 8 \\
\hline 2. Vida & & & & $\mathrm{x}$ & & & & & & & & $\mathrm{x}$ & $\mathrm{x}$ & & & & 3 \\
\hline 3. Corpo-templo & & & & & & $\mathrm{x}$ & $\mathrm{x}$ & $\mathrm{x}$ & & & & & & & & & 3 \\
\hline 4. Coisa importante & $\mathrm{x}$ & & & & & & & & & & & & & & & & 1 \\
\hline 5. Movimento & & & & & & & & & & & $\mathrm{x}$ & & & & & & 1 \\
\hline
\end{tabular}

Fonte: Coleta de dados (2019).

Dentre as US percebemos que a de maior prevalência foi a de "conjunto de órgãos e peças conexos, como uma máquina". Entendemos que essa concepção de corpo reside numa visão centrada no paradigma newtoniano-cartesiano como aponta Nista-Piccolo e Moreira (2012a), destacando a hegemonia, fortemente presente nos diversos espaços educacionais formais e não formais. Podemos confirmar isso a 
partir da fala dos sujeitos: "em cada parte do nosso corpo tem várias peças que se encaixa" (SAD 2); "é como uma máquina, cada órgão tem sua função" (SAD 5).

Expressão como "peças que encaixam" e "conjunto de órgãos" revelam o entendimento de um corpo-máquina, manipulado em suas partes segundo os ajustes e reparos ao seu funcionamento (NISTA-PICCOLO; MOREIRA, 2012a; GONÇALVES, 2012).

Por se tratar de uma concepção dicotômica de corpo, ele se constitui num objeto mecânico a ser disciplinado, visando unicamente o seu aprimoramento, eficiência e produtividade. Para tanto, precisa ser adestrado para que corresponda segundo os padrões de submissão e acato às ordens vigentes (GONÇALVES, 2012; NISTA-PICCOLO; MOREIRA, 2012a; FOUCAULT, 2013).

O corpo fracionado, se traduz no entendimento dos sujeitos como: "uma conexão de músculos, nervos, ligamentos, ossos, órgãos e outros complementares que fazem o corpo funcionar" (SAD 14); "é humano e orgânico, cheio de órgãos" (SAD 15) e "cabeça, braço, barriga, perna" (SAD 16). Essa ideia ignora a totalidade do ser humano, pois trata de uma negação do corpo pela razão e traduz o que Foucault (2013) denomina corpos dóceis, receptíveis naturalmente à disciplina, controle e submissão.

Independentemente da condição de privação de liberdade, surge a necessidade da busca de novos valores rumo à mudança da concepção de corpomáquina, de um corpo-objeto para o corpo-sujeito, tendo em vista sua realidade e sua relação com os outros corpos. Assim, é possível o desenvolvimento de suas potencialidades como expressão viva da sua existencialidade. Um corpo ativo, capaz de se autossuperar, num “[...] contínuo reconstruir de si mesmo, que se manifesta na liberdade de movimentos corporais expressivos e criativos”, pois nele está impressa a cultura de um povo dentro de num contexto histórico, político e social (GONÇALVES, 2012, p. 110).

Na sequência, podemos destacar as USs que apontam o corpo como "vida", conforme a fala dos seguintes sujeitos: "porque para onde a gente vai ele tá junto" (SAD 4); "o corpo é vida [...] é a sensação de abraçar você e sentir-se bem consigo mesmo. [...] aceitar o outro como ele ê" (SAD 12). Le Breton (2012), afirma que antes de qualquer coisa a existência é corporal e é na relação com o mundo que surgem novas significações 
carregadas de sentidos e valores, culminando então, na vida individual e coletiva. Ainda ratifica que: "Pela corporeidade, o homem faz do mundo a extensão de sua experiência [...]", o que nos remete ao entendimento de que as falas dos sujeitos traduzem na sua essência, a condição natural e social do homem (LE BRETON, 2012, p. 8)

Ainda na perspectiva de um corpo dicotômico, a US “Corpo-templo" é revelada segundo retratam os sujeitos: "Um modo de se habitar o corpo bumano é tudo, porque ele é incrivel [...]" (SAD 7); "Um corpo é muito importante que a pessoa tem de cuidar" (SAD 8). Assmann (1995) se apropria de metáforas que existiram no sentido de controlar os corpos para definir esse corpo que chamou de corpo jardim fechado, enquanto sinônimo de templo ou morada do espírito. Essa metáfora, designa o homem que cultua sua alma, ou melhor, tem sua existência separada da sua essência e, para isso, se ajusta vivendo de acordo com os padrões socialmente impostos. $\mathrm{Na}$ tentativa de explicar melhor, o autor mencionado (ASSMANN, 1995) ilustra o papel determinante da cultura ao moldar corpos segundo suas convenções sociais.

Assmann (2012) parte da premissa que toda aprendizagem demanda de um conjunto de processos corporais complexos e dinâmicos, o que envolve de fato a corporeidade inteira. Aprender significa, sem dúvida, uma descoberta do novo. Com a expressão sociedade aprendente sugere que a sociedade como um todo entre em estado de aprendizagem, cuja educação possa cumprir sua tarefa social emancipatória.

As USs menos expressivas associam o corpo a "coisa", como na fala do SAD 1 "[...] corpo é uma coisa muito importante pra mim" que se resume a ideia de corpo útil, a qual Foucault (2013) em seus estudos o define força útil e também força de trabalho, quando é ao mesmo tempo corpo produtivo e corpo submisso. Aquele que se constitui sujeito obediente, suscetível a hábitos, regras e ordens, ou seja, facilmente manipulável.

E, por fim, uma que contempla o "movimento", segundo a fala do SAD 11: "É ruim porque quando você está privado de liberdade tem que que se acostumar com novas rotinas e até mudar seus movimentos do corpo". Esse sujeito enfatiza um corpo adaptável e nessa lógica, Foucault (2013, p. 132) destaca a privação como espaço que "impõe limitações, proibições ou obrigações". E esse poder disciplinar gerado a partir das regras condicionantes e imperativas, denota uma adaptação, 
própria das exigências que lhe são impostas segundo o contexto ao qual se insere, tornando-se assim um objeto de controle. Para tanto, recorremos ainda ao mesmo autor quando trata da mecânica do poder, ao afirmar que:

[...] ela define como se pode ter domínio sobre os corpos dos outros, não simplesmente para que façam o que se quer, mas para que operem como se quer, com a técnicas, segundo a rapidez e a eficácia que se determina. A disciplina fabrica assim corpos submissos e exercitados, corpos dóceis (FOUCAULT, 2013, p. 133).

A Tabela 2 nos mostra a pergunta direcionada aos agentes socioeducativos, nos deram possibilidades de 03 (três) US:

Tabela 2 - Unidades de significado da pergunta geradora aos agentes socioeducativos "O que é o corpo do adolescente em privação de liberdade?"

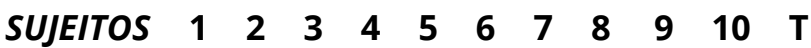

UNIDADES DE SIGNIFICADO

\begin{tabular}{l|l|l|l|l|l|l|l|l|l|l|l|}
\hline 1. Disciplinado & $\mathrm{x}$ & & & $\mathrm{x}$ & & & & $\mathrm{x}$ & $\mathrm{x}$ & $\mathrm{x}$ & 5 \\
\hline 2. Existencialidade & & $\mathrm{x}$ & $\mathrm{x}$ & & $\mathrm{x}$ & $\mathrm{x}$ & & & & & 4 \\
\hline 3. Corpo biológico & & & & & & & $\mathrm{x}$ & & & & 1 \\
\hline
\end{tabular}

Fonte: Coleta de dados (2019).

As expressões mais recorrentes seguem a perspectiva do corpo disciplinado, que podem ser dessa forma evidenciadas:

"[...] aprisiona junto sua mente e atitudes num contexto geral e precisam ser aprimorados $[\ldots . .] ".(S A S E ~ 1) ;$

"Um corpo que tem a perca da criatividade" (SASE 4);

"[...] perde o direito de ir e vir, como também o de escolhas [...]" (SASE 8);

"[...] o corpo é um espaço que o adolescente possa expressar sua identidade e individualidade em um ambiente que o mesmo deve seguir regras e costumes diferentes [...]" (SASE 9) $e$

"[...] um animal irracional trancado dia e noite sem ver o sol, sem ter contato com absolutamente ninguém da sua confiança" (SASE 10).

Tendo em vista o pensamento foucaultiano (FOUCAULT, 2013) esses discursos podem ser interpretados como fonte de domínio, obediência e controle do ser humano. Essas ações inclusive dão a noção de docilidade, estabelecendo possíveis mecanismos de poder sobre o corpo. 
Nessa concepção, o corpo parece ser visto como objeto manipulável, condição que é retirada do adolescente acautelado, sua autonomia e capacidade de decisão, cujas atividades são reguladas pela instituição, sobretudo porque sua vida íntima e seus significados serão invadidos e amplamente monitorados (DOMINGOS, 2014).

O que demonstra claramente o controle minucioso do corpo e de suas operações por meio da rotina das atividades diárias (SOUZA, 2019; DOMINGOS, 2014; FOUCAULT, 2013), buscando articulação entre o corpo e o objeto manipulado. Além do que se pode denominar de gerência sobre o tempo, há também a preocupação com a distribuição e organização destes corpos [adolescentes].

Para Foucault (2013), são várias as instituições como por exemplo: escolas, hospitais, hospícios, igrejas, fábricas, cadeias e outras, estas que docilizam corpos, reguladas pelo poder disciplinar, retirando indivíduos compulsoriamente do convívio familiar ou social, a fim de que possam ser moldados segundo os preceitos hegemônicos.

Althusser (2010) frisa que nossas atitudes e condutas derivam de aparelhos ideológicos e destaca as instituições como lugares de poder ligados a uma ideologia a qual o sujeito está submetido. Sendo assim, considera o Estado um meio de repressão capaz de manipular e controlar as massas, afirmando a existência de uma ideologia dominante no interior das instituições, uma vez que ensinam saberes práticos segundo suas normatizações. Os discursos dos agentes socioeducativos evidenciam uma clara percepção de corpo alienado, controlado no tempo e espaço, submisso às ordens impostas.

A US que destaca a "existencialidade" foi bem expressiva na fala dos agentes socioeducativos, como é possível verificar a seguir:

\footnotetext{
"Não deixa de ser humano" (SASE 2);

"O corpo é um estado de transformação permanente que pode influenciar na sua autoestima e na sua formação psicossocial [...]" (SASE 3);

"Se expressa de várias formas. Cada um de forma diferente dependendo da sua personalidade [...]" (SASE 5) e "[...] é um cidadão que por algum motivo alheio a sua vontade se envolveu em uma situação que o levou a cometer um ato, que o condicionou a conviver por um tempo determinado juntamente com outros adolescentes do seu mesmo perfil" (SASE 6).
} 
De modo geral, os apontamentos destacados se relacionam com os pressupostos da corporeidade como aponta Le Breton (2012), ao afirmar que todas as manifestações corporais são socialmente moduláveis, ou seja, os condicionantes sociais e culturais que modelam a corporeidade humana.

Compreendemos que falar sobre existencialidade requer de nós uma visão de mundo-vida para além da objetividade. Talvez seja por essa razão que os sujeitos investigados apresentam indícios de se pensar sobre o corpo a partir de uma ótica humana, dotada de significados.

Nóbrega (2005, p. 76) evidencia que "o mundo-vivido é a fonte para o conhecimento, é a partir das experiências vividas que atribuímos sentido aos acontecimentos. É pela ação que nos expressamos e a ação é corporal".

Ao pensarmos no corpo como estado de transformação, Gonçalves (2012) destaca que ele expressa a história individual e a história acumulada de uma sociedade. Portanto, se considera fundamental que "ser corpo [...], é estar atado a um certo mundo", condição inerente ao homem: ser sociável (MERLEAU-PONTY, 2011, p. 205).

No entanto, um sujeito destacou o corpo do ponto de vista biológico ao dizer que: "Corpo, estrutura fisica humana que fisiologicamente responde a todos os estímulos [...]” (SASE 7). Para nós, esse apontamento inclina-se mais diretamente às leis da anatomia e da fisiologia, uma identificação do corpo como fragmento. Nessa concepção, o homem é separado do corpo, como normalmente considera o senso comum ocidental. Le Breton (2012) entende que tal discurso enfatiza a fragilidade que o caracteriza, uma vez que, enquanto corporeidade, o corpo não pode ser concebido fora do contexto sociocultural a qual se insere.

A Tabela 3 apresenta a pergunta direcionada aos adolescentes se a prática esportiva educa e como, a qual encontramos as seguintes US: 
Tabela 3 - Unidades de significado da pergunta geradora aos adolescentes "A prática esportiva educa? Como?"

\begin{tabular}{|c|c|c|c|c|c|c|c|c|c|c|c|c|c|c|c|c|c|}
\hline $\begin{array}{l}\text { SUJEITOS } \\
\text { UNIDADES DE } \\
\text { SIGNIFICADO }\end{array}$ & 1 & 2 & 3 & 4 & 5 & 6 & 7 & 8 & 9 & 10 & 11 & 12 & 13 & 14 & 15 & 16 & $\mathrm{~T}$ \\
\hline $\begin{array}{l}\text { 1. Sim. Momento } \\
\text { de distração, } \\
\text { relaxamento e } \\
\text { aprendizado de } \\
\text { valores e cultura }\end{array}$ & & & $x$ & & $x$ & & & & $x$ & $x$ & $x$ & $x$ & & & $x$ & $x$ & 8 \\
\hline $\begin{array}{l}\text { 2. Sim. Criando } \\
\text { hábitos, } \\
\text { evidenciando o } \\
\text { cumprimento de } \\
\text { regras e da } \\
\text { disciplina }\end{array}$ & $x$ & & & $x$ & & & $x$ & $x$ & & & & & $x$ & & & & 5 \\
\hline $\begin{array}{l}\text { 3. Sim. Saúde física } \\
\text { e mental }\end{array}$ & & $x$ & & & & $x$ & & & & & & & & $x$ & & & 3 \\
\hline
\end{tabular}

Fonte: Coleta de dados (2019).

Majoritariamente todos os adolescentes afirmaram que a prática esportiva educa. No entanto, as justificativas divergem na medida que trazem apontamentos frente as suas especificidades.

A US com maior expressividade que consistiu em responder como o esporte educa aponta o momento de distração, relaxamento e aprendizado de valores e cultura, sendo, nas falas:

"[...] ela tem várias formas de educar, mais você mesmo que faz sua escolha, você que segue seus objetivos [...]"

(SAD 2); "[...] fazendo esportes você tem que respeitar, tem que ser unido e outras coisas que podemos dizer que tem gente que só aprende no esporte." (SAD 5);

"[...] esporte é uma distração para o corpo tipo como o modo humano está estressado, pratica o esporte, acalma" (SAD 9);

"[...] ajuda bastante em relação a educação, pois é um momento de distração e aprendizado" (SAD10);

"[...] fazem para adquirir conhecimento" (SAD11);

"[...] as práticas esportivas ensinam a ser humilde, a ter grandes responsabilidades, a ter educação, e perdoar o próximo ensina um novo conceito de vida da parte de qualquer prática de esporte desde o mais simples até o mais extremo, pois esporte é vida é cultura em alguns pontos de vista esporte é tudo pois tem pessoas que vivem desses esporte para trabalho e até outras finalidades esportivas, então se não tem esporte não a vida com sentido esporte é show é esporte espetacular..." (SAD12);

"[...] educa de uma forma sutil é fácil de educar uma pessoa enquanto está jovem ou adolescente"; (SAD15) e

"Educação respeito humildade" (SAD16). 
De acordo com os argumentos apresentados, Gaya (2006, p. 107) afirma que,

[...] joga-se pela alegria da auto-superação da beleza estética. Pratica-se esporte na perspectiva do autoconhecimento, da alegria da participação, pelo prazer de um corpo flexível, resistente, ágil e saudável. Privilegia-se o companheirismo. Enfatizam-se preocupações com o lúdico, a saúde, a estética e o bem-estar.

O esporte enquanto fenômeno sociocultural na instituição socioeducativa, assume o papel fundamental na formação humana e cidadã dos adolescentes. Principalmente por se tratar de um momento no qual eles podem, ludicamente, demonstrar quem são na sua essência e usufruir de algo — para eles — altamente atrativo e interessante. $\mathrm{Na}$ instituição supracitada, o esporte transcende o olhar para além do saber-fazer e ainda possibilita aos adolescentes aprenderem a importância do espírito coletivo, da solidariedade e da educação.

Mezzaroba (2008) evidencia que a prática de atividades esportivas gera em seus praticantes efeitos compensatórios que, de alguma forma, afastam as tensões do cotidiano, gerando assim prazer e inibindo o ato violento que não é bem visto na sociedade, ou seja, o esporte assume o seu papel educativo, socializador e humano.

A prática de esporte atrelada à dualidade do corpo físico e mental, evidenciada pelos adolescentes, encontra-se claramente condicionadas à perspectiva de uma vida saudável, proporcionando sobretudo benefícios ao corpo, como por exemplo a diminuição dos riscos de doenças, potencializando a longevidade. Tal pensamento remete a uma forma dicotomizada de corpo como se fosse viável dissociá-lo, conforme apontam as falas:

"[...] sua mente é seu guia [...]" (SAD 2); "[...] forma de manter a vida física e saudável." (SAD 6) e "[...] ela educa pelo fato de quando uma pessoa pratica uma atividade esportiva não só o corpo como também o cérebro está em constante funcionamento, e é a partir do cérebro que saem os comandos para a movimentação do corpo, como uma engrenagem de um motor. Este comando de cérebro educa o corpo na sua coordenação motora facilitando a sua movimentação. Com o corpo bem o ser humano vive bem e com sua saúde em dia" (SAD 14).

Embora a compreensão do discurso dos sujeitos seja voltada à saúde corporal, é nítida a presença hegemônica e dicotômica do corpo atrelada ao senso comum. Entendemos, à luz dessa percepção, o esporte enquanto instrumento de 
manipulação, alienação ou até mesmo mera reprodução de valores positivos e/ou negativos.

Precisamos entender a prática esportiva não necessariamente baseada na reprodução de movimentos, para mero cumprimento do eixo esporte dentro da medida socioeducativa, mas sim, na capacidade de se envolver por completo a partir dos princípios salutares necessários ao desenvolvimento humano (MOREIRA; SIMÕES, 2018; MOREIRA; SIMÕES, 2016; NISTA-PICCOLO; MOREIRA, 2012b).

Quando os agentes socioeducativos foram questionados se a prática esportiva educa, pudemos evidenciar duas US, na Tabela 4:

Tabela 4 - Unidades de significado da pergunta geradora aos agentes socioeducativos "A prática esportiva educa? Como?"

\begin{tabular}{|c|c|c|c|c|c|c|c|c|c|c|}
\hline SUJEITOS & 12 & 3 & 4 & 5 & 6 & 7 & 8 & 9 & 10 & $\mathrm{~T}$ \\
\hline $\begin{array}{l}\text { 1. Sim. Disciplina, regras, superação de limites, } \\
\text { convívio social e bem-estar }\end{array}$ & $\mathrm{x} \quad \mathrm{x}$ & $\mathrm{x}$ & $\mathrm{x}$ & $\mathrm{x}$ & $\mathrm{x}$ & $\mathrm{x}$ & & $\mathrm{x}$ & $\mathrm{x}$ & 9 \\
\hline 2. Não. Dependerá das escolhas pessoais & & & & & & & $x$ & & & 1 \\
\hline
\end{tabular}

A US de maior representatividade foi "Disciplina, regras, superação de limites, convívio social e bem estar", todos os sujeitos são unânimes ao afirmar que a prática esportiva educa, demonstrando a importância do fenômeno esporte dentro do socioeducativo. Tal argumento exprime no discurso dos sujeitos:

"[...] a partir do momento em que o adolescente se sinta útil na prática de esportes ele começa a se sentir bem com ele próprio tornando isso parte do seu processo de ressocialização e interação com outras pessoas" (SASE 1);

"[...] porque através dela é possivel relacionarmos uns com os outros, nela estamos em convívio com diferentes culturas" (SASE 2);

"[...] pode-se acrescentar na vida do adolescente os limites que as vezes ele desconhece, o trabalho em grupo, o companheirismo, as certezas alcançadas pelo esforço e dedicação, a humildade, ainda muitas vezes no reconhecimento que se o adversário naquele momento foi melhor" (SASE 3);

"[...] através da disciplina que é passada pelo esporte além da ajuda no convívio social através da coletividade que é passada" (SASE 4); "[...] desenvolve a capacidade de trabalho em grupo, respeito ao próximo, controle emocional, superação de seus limites" (SASE 5); "[...] por várias disciplinas aplicadas e executadas em diversas modalidades esportivas [...]." 
(SASE 6); "[...] traz consigo regras, limites, trabalhando em equipe, a fim de um bem comum, com isso se instruindo de forma correta, o esporte educa e transforma, despertando no adolescente um elo entre a prática esportiva e a vida [...]."

(SASE 7); "[...] ensino o mesmo a práticas de convivência, seguir regras e aprender, de certa forma, a conviver e a socializar"

(SASE 9) e "[...] evita depressão, aumenta a vontade de viver e de ser feliz" (SASE 10).

Essa visão dos agentes socioeducativos, mesmo acreditando que a prática esportiva educa, está sumariamente atrelada à forma como tem se estruturado dentro da instituição, reforçando por meio de um poder disciplinar, uma educação pautada na disciplinarização do corpo.

Por essa razão, o esporte atua como um considerável aliado rumo à formação dos adolescentes quanto ao uso das regras, na lógica da moral. Souza (2019) no seu estudo tece crítica ao esporte, não contrária a sua prática, mas sim a sua atual abordagem, que segundo a mesma, contribui para uma formação moldada a certos padrões sociais, de acordo com os preceitos modernos que homogeneízam as diferenças.

Verificou-se a menção do esporte como ferramenta capaz de proporcionar a superação de limites, o trabalho da coletividade e o bem-estar. Nesse interim, concordamos com o pensamento de Moreira e Simões (2018, p. 227, grifo nosso) ao afirmar que, o esporte destaca:

[...] valores como reconhecer a própria potencialidade e a do outro, sua capacidade e a do outro, e suas limitações e as do outro permitem ao sujeito a compreensão de seu papel no grupo, da função de seus companheiros e, até mesmo, da de seus adversários.

Há que se ressaltar o posicionamento de um agente socioeducativo, assim enunciando:

[...] Não adianta oferecer inúmeras atividades ou oportunidades, se o indivíduo não querer mudança. Se meios externos fosse solução para mudança, educação ou formação de caráter, a sociedade numa forma geral seria muito mais evoluída. (SASE 10).

Com base nisso é visível a depreciação em relação ao cenário socioeducativo como passível de qualquer mudança, o que nos remete a um reforço a discursos dominantes que perpetuam a ideia remota, mas ainda presente em vários discursos, 
aos quais, Foucault (2013) já sinalizava o nascimento das prisões como oriundo da necessidade de se afastar do convívio social os corpos infratores.

Se partirmos do pressuposto que os agentes socioeducativos deveriam acreditar na mudança dos adolescentes, visando a ressocialização e ressignificação de valores e atitudes a partir do discurso apontado, vê-se a necessidade de se sinalizar quais os verdadeiros sentidos e significados da sua profissão num centro socioeducativo, sob a égide de um caráter educativo e não, punitivo.

\section{Considerações finais}

Esse estudo nos permitiu refletir sobre dois eixos que podem ser evidenciados como pilares dessa investigação: o olhar acerca da percepção de corpo e o potencial educativo do esporte. Todavia, os discursos dos adolescentes e dos agentes socioeducativos partem para caminhos, ora divergentes, ora convergentes.

Dessa forma, podemos destacar que os adolescentes compreendem o corpo a partir de uma ótica fortemente arraigada numa dimensão "apenas" biológica e fisiológica, mostrando que ainda é existente a visão fragmentada e pautada na dicotomia, que ignora a totalidade do ser humano e sua complexidade dialética.

Em relação aos agentes socioeducativos, o fato de se tratar de um local de segurança pública, por si só denota o quanto as respostas carregam o estigma de subordinação ao controle e disciplina, tornando-se um veículo de perpetuação de uma ideologia dominante, centrada no poder. Vê-se aqui o sentido do entendimento de um ser passivo, obediente e desvinculado de um compromisso transformador.

Quanto ao entendimento, se a prática esportiva educa e como todos os sujeitos partícipes concordaram que sim, embora com posicionamentos distintos no tocante ao "como", o que traduz para os adolescentes numa necessidade própria da natureza humana de expressar naturalmente sua riqueza sensorial, permitindo sentir, pensar e agir em sua realidade existencial. Já os agentes socioeducativos, ainda que outros pensem de modo diferente, a maioria apresentou um discurso de enaltecimento à disciplina e a regras, por exemplo, vê-se claramente uma visão individualista que mascara, oculta e perpetua as relações de poder.

Em síntese, é urgente o entendimento da concepção de corpo na perspectiva da corporeidade, de tal modo que privilegie o ser na sua essência e totalidade. Além 
da necessidade de maior compreensão da prática esportiva enquanto meio eficaz de possibilidades educativas nas instituições socioeducativas, compreendendo a dinâmica de seu desenvolvimento e, especialmente, reconhecendo que os adolescentes podem desenvolver suas melhores qualidades e potencialidades humanas, se encorajados.

Logo, são indispensáveis mais estudos, pesquisas e reflexões sobre o corpo e o esporte nestas instituições privativas de liberdade, de modo que possam incentivar os profissionais efetivamente envolvidos a ousarem no planejamento e desenvolvimento das atividades diárias, junto aos adolescentes, em cumprimento de medida socioeducativa, para que não repitam as práticas hegemônicas de corpos dóceis e um esporte vazio e sem significado.

\section{Referências}

ALTHUSSER, L. Ideologia e Aparelhos Ideológicos do Estado: notas sobre os aparelhos ideológicos de Estado. 11. ed. Rio de Janeiro: Edições Graal, 2010.

ASSMANN, H. Reencantar a educação: rumo à sociedade aprendente. 12. ed. Petrópolis: Vozes, 2012.

ASSMANN, H. Paradigmas educacionais e corporeidade. 3. ed. Piracicaba: Unimep, 1995.

BENTO, J. O. Desporto: discurso e substância. Porto: Campo das Letras Editores, 2004.

BRASIL. Estatuto da Criança e do Adolescente. Lei no 8.069 de 13 de julho de 1990. Dispõe sobre o Estatuto da Criança e do Adolescente e dá outras providências. Disponível em: http://www.planalto.gov.br/ccivil_03/leis/L8069.htm. Acesso em: 25 set. 2019.

DOMINGOS, R. S. Pensando e Praticando o Esporte na Medida Socioeducativa: Orientações para Profissionais de Educação Física. 152 p. Dissertação (Mestrado Profissional) Universidade Anhanguera de São Paulo, São Paulo, 2014.

FOUCAULT, M. Vigiar e punir: nascimento da prisão. 41. ed. Petrópolis: Vozes, 2013.

GAYA, A. Corpos esportivos: o esporte como campo de investigação. In: TANI, G.; BENTO, J. O.; PETERSEN, R. D. S. Pedagogia do Desporto. Rio de Janeiro: Guanabara Koogan, 2006. p. 101-111.

GIL, A. C. Como elaborar projetos de pesquisa. 6. ed. São Paulo: Atlas, 2017.

GIORGI, A. Psicologia como ciência humana: uma abordagem de base fenomenológica. Belo Horizonte: Interlivros, 1978.

GONÇALVES, M. A. S. Sentir, pensar, agir: corporeidade e educação. 15. ed. Campinas, SP: Papirus, 2012. 
KUNZ, E. Transformação didático-pedagógica no esporte. 8. ed. Ijuí: Unijuí, 2014.

KUNZ, E. (org.). Didática da educação física 2. 4. ed. Ijuí: Unijuí, 2012.

LE BRETON, D. A sociologia do corpo. 6. ed. Rio de Janeiro: Vozes, 2012.

MACEDO, R. S. Etnopesquisa crítica, etnopesquisa-formação. Brasília: Liberlivro, 2010.

MARTINS, J.; BICUDO, M. A. V. A pesquisa qualitativa em psicologia: fundamentos e recursos básicos. São Paulo: Centauro, 2005.

MERLEAU-PONTY, M. Fenomenologia da percep̧ção. 4. ed. São Paulo: Editora WMF Martins Fontes, 2011.

MEZZAROBA, C. O esporte nos projetos sociais: reflexões através das contribuições de Norbert Elias. Revista Digital, Buenos Aires, n. 124, ano 13, set. 2008.

MINAS GERAIS (MG). Subsecretaria de Atendimento as Medidas Socioeducativas [SUASE]. Diretrizes Pedagógicas para Atendimento Educacional ao Sistema Socioeducativo no Estado de Minas Gerais. 2016.

MOREIRA, W. W. Formação Profissional em Ciência do Esporte: Homo Sportivus e Humanismo. In: BENTO, J. O.; MOREIRA, W. W. O Homo sportivus: o humano no homem. Belo Horizonte: Instituto Casa da Educação Física, 2012. p. 113-178.

MOREIRA, W. W.; SIMÕES, R. M. R. Educação Física, esporte e corporeidade: associação indispensável. In: MOREIRA, W. W.; NISTA-PICCOLO, V. L. (Orgs.). Educação Física e Esportes no século XXI. Campinas: Papirus, 2016. p. 133-149.

MOREIRA, W. W.; SIMÕES, R. M. R. Esporte e humanismo. In: MOREIRA, W. W.; SILVA, J. V. P. (Orgs). Lazer e esporte no século XXI: novidades no horizonte? Curitiba: InterSaberes, 2018. p. 161-177.

MOREIRA, W. W.; SIMÕES, R. M. R. Educação Física, Corporeidade e Motricidade: criação de hábitos para a educação e para a pesquisa. In: DE MARCO, A. (Org.). Educação fisica: Cultura e sociedade. 6. ed. Campinas: Papirus, 2011.

MOREIRA, W. W.; SIMÕES, R. M. R..; PORTO, E. Análise de conteúdo: técnica de elaboração e análise de unidades de significado. Revista Brasileira Ciência e Movimento, v. 13, n. 4, 2005. p. 107-114.

NISTA-PICCOLO, V. L.; MOREIRA, W. W. Esporte como conbecimento e prática nos anos iniciais do ensino fundamental. São Paulo: Cortez, 2012a.

NISTA-PICCOLO, V. L.; MOREIRA, W. W. Esporte para a vida no ensino médio. São Paulo: Cortez, 2012b.

NÓBREGA, T. P. Corporeidade e Educação Física: do corpo-objeto ao corpo-sujeito. Natal: Editora da UFRN, 2005.

REZENDE, A. M. de. Concep̧̧ão fenomenológica da educaşão. São Paulo: Cortez, 1990. 
SANTIN, S. Perspectivas na visão da corporeidade. In: MOREIRA, W. W. (Org.). Educação física \&o esportes: Perspectivas para o século XXI. Campinas: Papirus, 2011. p. 51-69.

SILVA, F. S.; RUBIO, K. Um jeito novo de jogar: o futebol libertário. Revista Brasileira de Psicologia do Esporte, v. 2, n. 2, 2008.

SOUZA, C. M. Educando o corpo desvalido: a educação física na história da privação de liberdade de crianças e jovens brasileiros. Revista Movimento, Porto Alegre, v. 25, e25057, p. $1-12,2019$.

VOLPI, M. O adolescente e o ato infracional. 9. ed. São Paulo: Cortez, 2011.

RECEBIDO: $11 / 04 / 2020$

APROVADO: $24 / 07 / 2020$

RECEIVED: 04/11/2020

APPROVED: 07/24/2020

RECIBIDO: $11 / 04 / 2020$

APROBADO: 07/24/2020 